\title{
Can You See the Heat? - Using a Thermal Imaging Camera in the Chemistry Classroom
}

\author{
Claudia Bohrmann-Linde ${ }^{*}$, Simon Kleefeld \\ Department of Chemistry Education, University of Wuppertal, Gaußstr, 20, 42119 Wuppertal, Germany \\ *Corresponding author: bohrmann@uni-wuppertal.de
}

Received January 12, 2019; Revised February 15, 2019; Accepted April 09, 2019

\begin{abstract}
Thermal imaging cameras can be a very useful help when observing chemical experiments. They enable the observation of phenomena which are not visible to the human eye. In this paper a set of school experiments is described in which the use of a thermal imaging camera gives additional information on ongoing processes. Additionally an e-book that was designed as accompanying learning material is presented.
\end{abstract}

Keywords: thermal imaging camera, thermal energy, IR radiation, energy turnover, chemical reactions, sensor, hands-on experiments, e-book, digital media, chemistry classroom

Cite This Article: Claudia Bohrmann-Linde, and Simon Kleefeld, "Can You See the Heat? - Using a Thermal Imaging Camera in the Chemistry Classroom." World Journal of Chemical Education, vol. 7, no. 2 (2019): 179-184. doi: 10.12691/wjce-7-2-18.

\section{Introduction}

Thermal imaging cameras (TIC) are used in various military, industrial, research and civil applications. As the name suggests, TICs are cameras that can visualise thermal energy which is invisible to the human eye. Thermal imaging cameras have an IR-transmissive objective and the IR-radiation emitted by an object reaches a detector matrix of sensors that are sensitive to a part of the spectrum of infrared light, the thermal IR between 3 and $14 \mu \mathrm{m}$ (Figure 1).

The recording of the IR-radiation is based on the temperature-dependence of the electrical resistance. IR-radiation reaching the resistors of the detector matrix in the camera leads to a change in electrical resistance which is then translated into a signal. The output of a TIC is a thermogram. It is a false colour representation produced by the accompanying software. Thermograms give information about the temperature profile of the object under scrutiny. They contain a colour bar with a colour gradient assigning a colour to a respective temperature. If there are great changes in temperature during the recording of a video, the colour code bar at the side of the thermogram might change. Thus one cannot say that a specific colour represents a characteristic temperature.

If there is a temperature gradient on a surface, the thermogram shows a colour gradient (Figure 2 top right). If all of the objects have the same temperature, the thermogram shows a uniformly coloured area (Figure 2 bottom right).

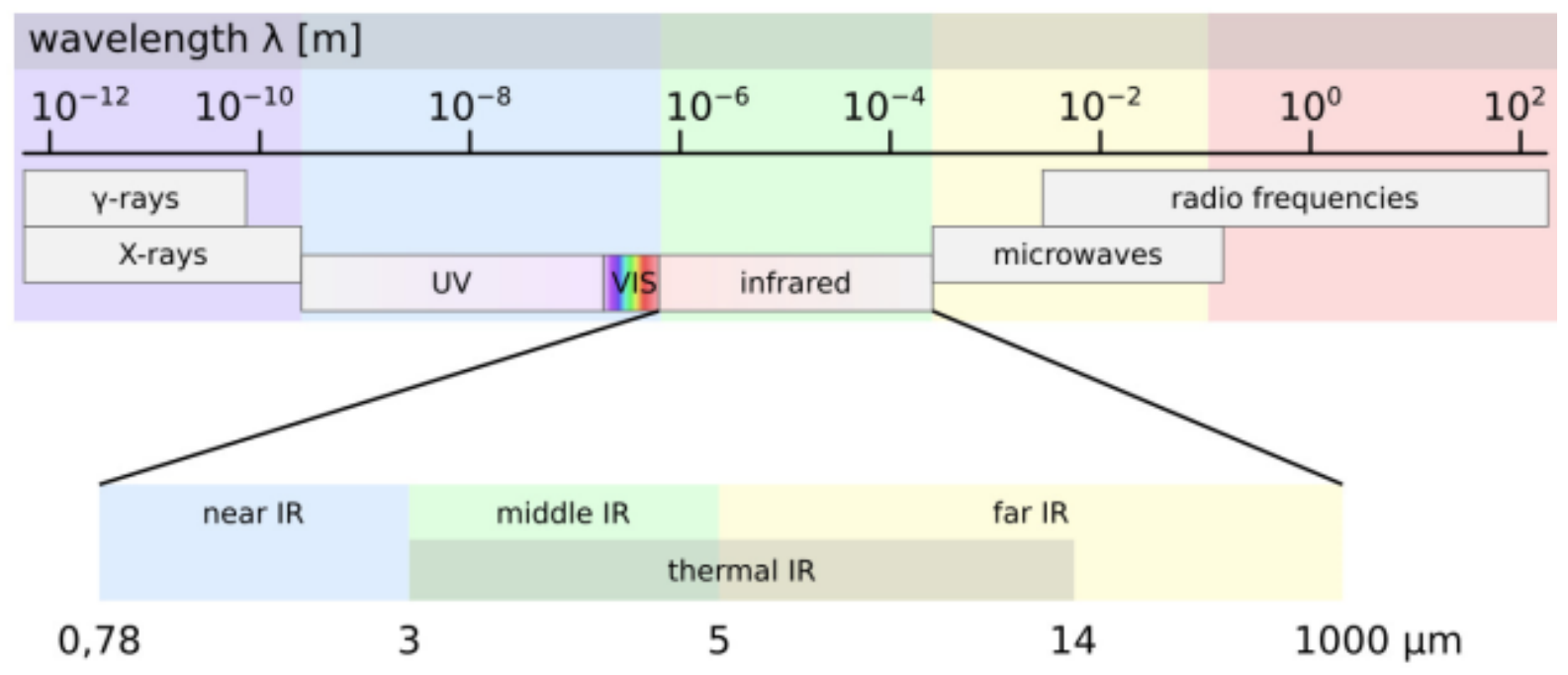

Figure 1. Electromagnetic spectrum. The sensors of TICs are sensitive to the emission of IR-radiation between 3 and $14 \mu \mathrm{m}$ 


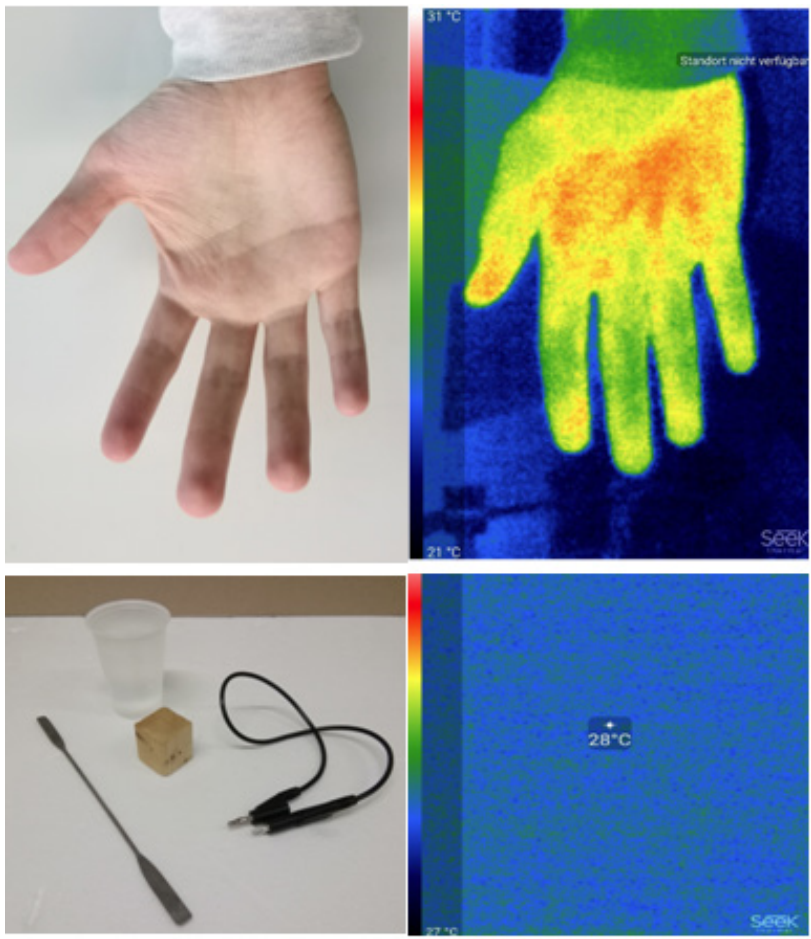

Figure 2. Photographs and thermograms of a hand with different areas of surface temperatures (top) and of objects of the same temperature (bottom)

Thermal imaging cameras are comparatively inexpensive and can be connected to a smart phone or tablet. For our experiments we used the model Seek Thermal Compact $X R$ (appr. 260US\$) which can be operated via the free app Seek Thermal. The camera detects IR radiation between 7.2 and $13 \mu \mathrm{m}$, thus covering a temperature range from $-40^{\circ} \mathrm{C}$ to $330^{\circ} \mathrm{C}$. The camera gives out pictures as jpg- or videos as mp4-files. It is recommended to use an extension cable and to fix the camera at a stand to avoid strongly blurred pictures.

Using TICs in the science classroom is very attractive as it offers an additional, different view on processes taking place during experiments. It is a contactless measurement and a great number of temperatures at different points of the surface are recorded at once, giving a picture displayed by the thermogram, eventually leading to temperature profiles of a surface. Also the flow of thermal energy across a surface can be visualised. So far thermal imaging cameras have been proposed mainly for teaching physics $[1,2,3]$. There are very few publications in chemical education literature, one of them with focus on evaporation, condensation, latent heat, convection etc. [4].

\section{Preliminary Considerations}

Before experimenting one should get oneself acquainted with the use of the TIC and realize that there are some practical limitations [5]. It should be taken into account that some media such as glass are IR-intransparent (Figure 3a) and that one should avoid the reflection of heat, e.g. at metal surfaces (Figure 3b). So experiments should be carried out in petri dishes or viewed from a bird's eyes perspective. Choosing the right observation angle or attaching a piece of scotch tape on the surface of a metal strip can prevent undesired reflections of IR radiation.
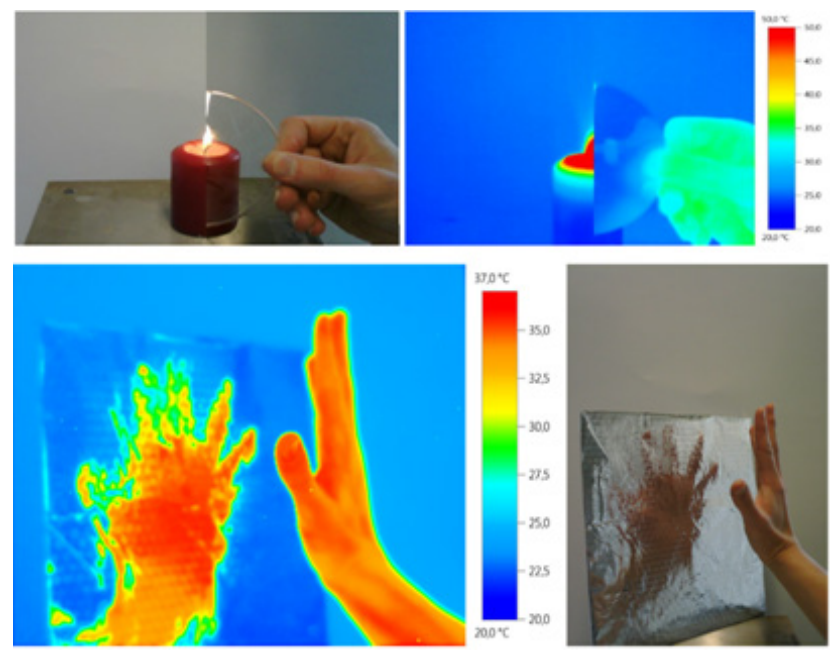

Figure 3. Visual pictures and thermograms show that glass is IRintransparent (top) and that a metal surface can reflect IR-radiation (bottom)

From a theoretical point of view it should be kept in mind, that there are several additional factors influencing the measurement with a thermal imaging camera such as absorption of heat by ambient air humidity or carbon dioxide [6] or emission of additional heat by warm objects close to the object to be studied. In the following experiments the TIC is used only for qualitative interpretations.

\section{Experiments}

In order to get familiar with the TIC some introductory experiments can be carried out. Following this we will focus on experiments suitable for the chemistry classroom in this paper. In the e-book described in the last section there are more experiments, some of which are more related to physics, which are described and partially documented via videos in the e-book. For all experiments a thermal imaging camera which is connected to a mobile device, e.g. smartphone or tablet with the respective app is needed. Before starting the experiments connect the TIC to your mobile device and start the app, e.g. Seek Thermal. Focus on the relevant area of interest before starting a reaction. Prior to the experiment it is sometimes helpful to place a cold or hot object as a "landmark" next to the site of the experiment to see where the camera is aiming at.

\subsection{Getting Started-thermograms as Output of TICs}

\subsubsection{Material and Chemicals}

Three plastic cups of similar material but different colour, three identical transparent plastic cups, $400 \mathrm{~mL}$ hot water (about $70^{\circ} \mathrm{C}$ ), $100 \mathrm{~mL}$ cold water (about $10^{\circ} \mathrm{C}$ ), $100 \mathrm{~mL}$ water at room temperature. 


\subsubsection{Procedure}

a) Equal amounts of about $100 \mathrm{~mL}$ of hot water are filled into three cups that are of identical material but different in colour.

b) Three identical transparent cups are put on a table and filled with cold, hot water and water of about room temperature.

\subsubsection{Observation and Remarks}

Even though the cups look different to the human eye, one cannot distinguish them in the thermogram as the water has the same temperature in all three cups. In contrast, the three transparent cups look identical to the human eye but the thermograms look different as the water has a different temperature in each cup.

This introductory experiment can be used to demonstrate that our observation of experiments for which we rely on our own senses can be augmented by impressions obtained from the sensor of the TIC.

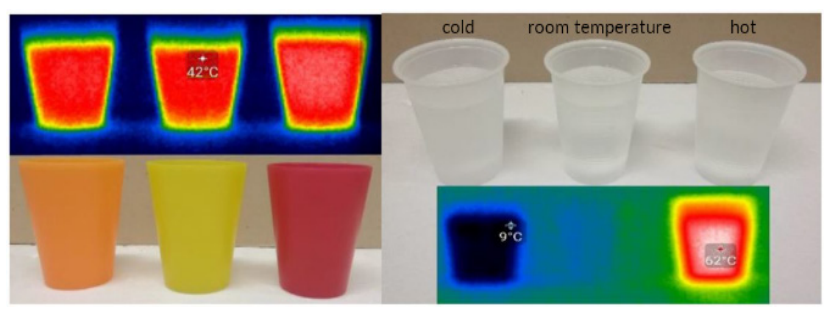

Figure 4. Warm water in differently coloured cups (left side) and water of different temperatures in identical cups (right side)

\subsection{Solvation Processes}

\subsubsection{Hazards}

Ammonium nitrate is oxidizing and flammable. Keep away from fire. Sodium hydroxide is caustic. Wear safety goggles. Neutralize the sodium hydroxide solution before draining.

\subsubsection{Material and Chemicals}

Spot plate, pipette, spatula, small quantities of solid potassium chloride $\mathrm{KCl}$, sodium hydroxide $\mathrm{NaOH}$ and ammonium nitrate $\mathrm{NH}_{4} \mathrm{NO}_{3}$.

\subsubsection{Procedure}

Fill $1 \mathrm{~mL}$ water each into three dents of a spot plate. Simultaneously add a spatula-tip full of the three salts into a different dent each.

\subsubsection{Observation and Remarks}

To the naked eye the three salts seem to behave similarly: all three dissolve in the water giving a colourless, clear solution. With the TIC a difference becomes obvious: whereas the sodium hydroxide dissolves in an exothermic process, the dissolution of potassium chloride and ammonium nitrate is endothermic.

The process of dissolution can be followed, witnessing the increase and decrease in temperatures. This can be used to talk about enthalpy of dissolution with regard to lattice energy and hydration energy.

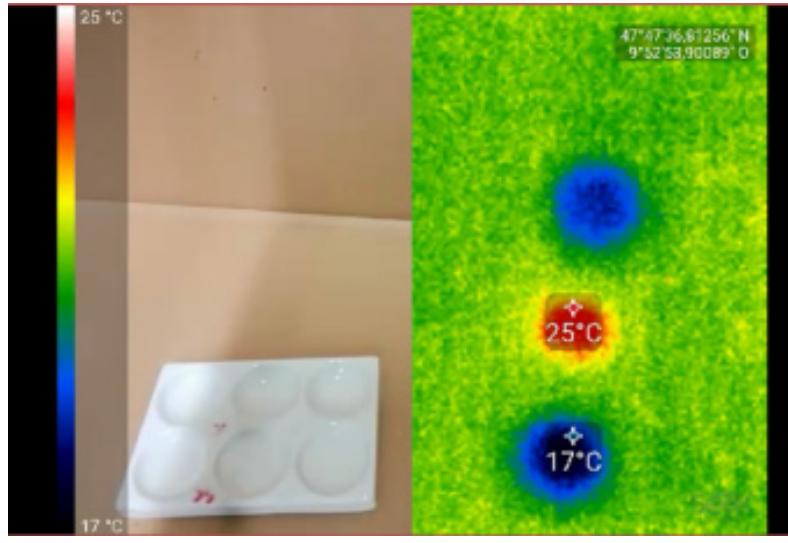

Figure 5. The visual picture shows optically similar results whereas the thermogram reveals differences in heat of solution

\subsection{Neutralisation Reaction}

\subsubsection{Hazards}

Wear safety goggles. Hydrochloric acid is corrosive. Sodium hydroxide is caustic. Before draining, neutralize the solutions.

\subsubsection{Material and Chemicals}

Petri dish, pipette, hydrochloric acid, $\mathrm{c}(\mathrm{HCl})=0.1 \mathrm{~mol} / \mathrm{L}$, sodium hydroxide solution, $\mathrm{c}(\mathrm{NaOH})=0.1 \mathrm{~mol} / \mathrm{L}$.

\subsubsection{Procedure}

Fill a petri dish half-full with hydrochloric acid. Add some sodium hydroxide solution dropwise into the acid and watch the solution after addition of each drop.

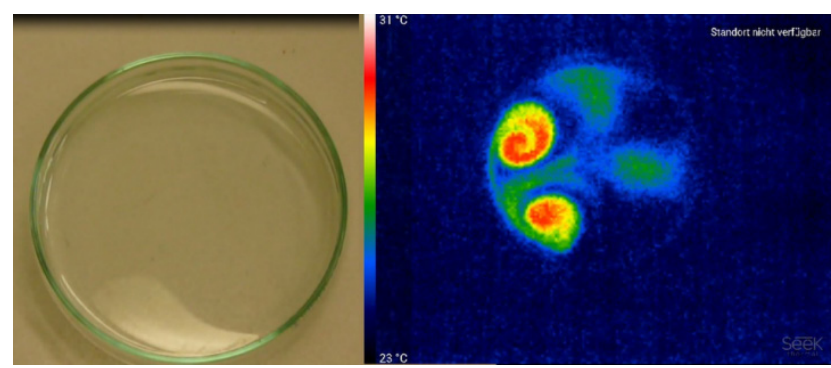

Figure 6. The exothermic character of a neutralisation reaction can be impressively shown by using a TIC

\subsubsection{Observation and Remarks}

Again a colourless solution can be seen. Immediately after adding a few drops of sodium hydroxide solution one can see some whirls moving through the solution. The reaction taking place is a neutralisation reaction of hydrochloric acid and sodium hydroxide solution, which is an exothermic process. The TIC provides the observer with very aesthetical impressions. Also the site of the neutralisation in the solution can be observed, just like the spreading of thermal energy through the sample.

\subsection{Entropy-driven Reaction}

\subsubsection{Hazards}

Wear safety goggles. Citric acid and sodium carbonate pentahydrate can be irritant to the eyes. 


\subsubsection{Material and Chemicals}

Petri dish, spatula, sodium carbonate pentahydrate $\mathrm{Na}_{2} \mathrm{CO}_{3} \cdot 5 \mathrm{H}_{2} \mathrm{O}(\mathrm{s})$, citric acid $\mathrm{C}_{6} \mathrm{H}_{8} \mathrm{O}_{7}$ (s)

\subsubsection{Procedure}

Put two spatula-tips full of sodium carbonate pentahydrate on one half of a petri dish and two spatulatips full of citric acid on the other half of the same petri dish. Turn on the camera and mix the two substances by making a z-shaped stroke with a spatula through the heaps of white powders.

\subsubsection{Observation and Remarks}

After a short time a visible production of a colourless gas can be observed and a liquid forms at the places where both reactants have contact with each other. The reaction takes place autonomously. The thermogram reveals that the temperature decreases strongly at the reaction sites.

The reaction taking place is an endothermic but exergonic process. This reaction is one of the few examples of these kinds of reactions that can take place because of a substantial rise in entropy. Contrary to the well-known version with barium hydroxide octahydrate and ammonium thiocyanate this version can be carried out as students' experiment with harmless substances. The reaction products are carbon dioxide gas, water and sodium citrate.

$$
\begin{aligned}
& 2 \mathrm{C}_{6} \mathrm{H}_{8} \mathrm{O}_{7}(\mathrm{~s})+3 \mathrm{Na}_{2} \mathrm{CO}_{3} \cdot 5 \mathrm{H}_{2} \mathrm{O}(\mathrm{s}) \rightarrow \\
& \quad 3 \mathrm{CO}_{2}(\mathrm{~g})+18 \mathrm{H}_{2} \mathrm{O}(\mathrm{l})+2 \mathrm{C}_{6} \mathrm{H}_{5} \mathrm{O}_{7} \mathrm{Na}_{3}(\mathrm{aq})
\end{aligned}
$$

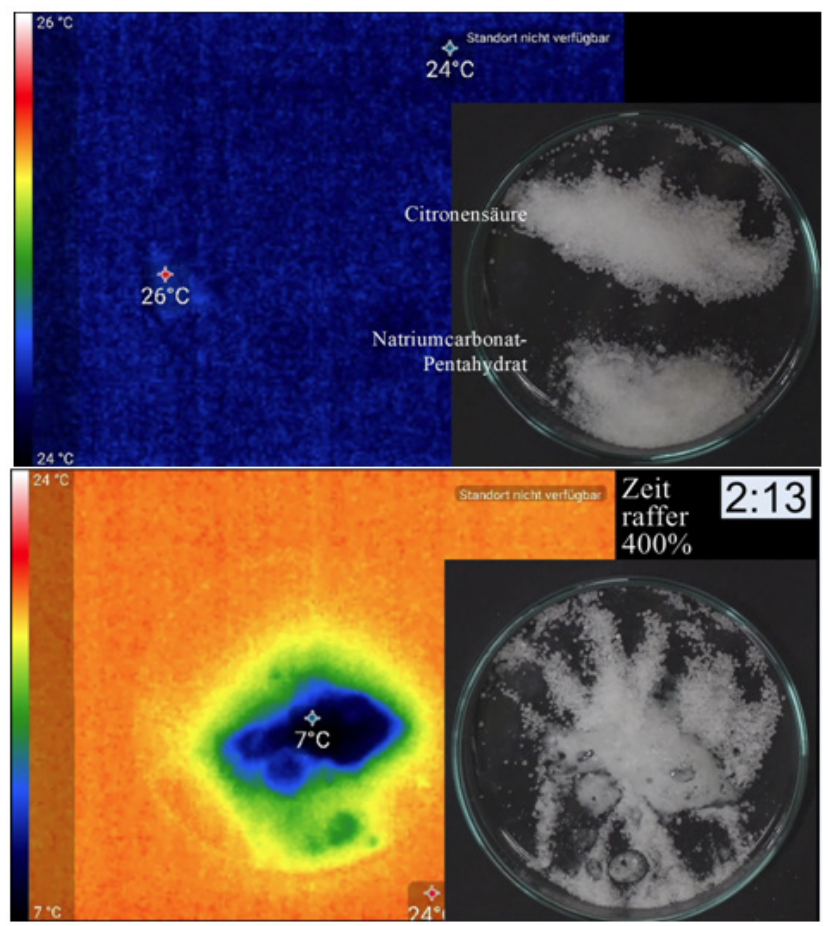

Figure 7. Observations before and after mixing the reactants sodium carbonate pentahydrate and citric acid of the entropy-driven reaction

It is vital to take a hydrate of sodium carbonate, as the release of the water of crystallization strongly contributes to the entropy gain, besides the formation of the gas. If a video in dual mode (real picture and thermal image) is recorded, one can clearly see that the system cools down at the areas of contact of the reactants. In addition to the direct observation the TIC helps to see the energy turnover of the reaction.

\subsection{Chemiluminescence and Cold Light}

\subsubsection{Hazards}

Wear safety goggles. Sodium hydroxide solution is slightly caustic. Hydrogen peroxide solution is irritant and corrosive and should not contact eyes or be swallowed.

\subsubsection{Material and Chemicals}

$0.01 \mathrm{~g}$ luminol $\mathrm{C}_{8} \mathrm{H}_{7} \mathrm{~N}_{3} \mathrm{O}_{2}(\mathrm{~s}), 1 \mathrm{~mL}$ sodium hydroxide solution $\mathrm{NaOH}$ (aq), w $=5 \%, 1 \mathrm{~mL}$ hydrogen peroxide solution $\mathrm{H}_{2} \mathrm{O}_{2}(\mathrm{aq}), \mathrm{w}=30 \%$, potassium ferricyanide $\mathrm{K}_{3}\left[\mathrm{Fe}(\mathrm{CN})_{6}\right], \mathrm{w}=2.5 \% .150 \mathrm{~mL}$ beaker, $400 \mathrm{~mL}$ beaker.

\subsubsection{Procedure (taken from [7])}

Prepare $100 \mathrm{~mL}$ of an alkaline solution of luminol with $0.01 \mathrm{~g}$ luminol $\mathrm{C}_{8} \mathrm{H}_{7} \mathrm{~N}_{3} \mathrm{O}_{2}(\mathrm{~s}), 1 \mathrm{~mL}$ sodium hydroxide solution $\mathrm{NaOH}(\mathrm{aq}), \mathrm{w}=5 \%$, and $1 \mathrm{~mL}$ hydrogen peroxide solution $\mathrm{H}_{2} \mathrm{O}_{2}$ (aq), 30\%. Prepare $10 \mathrm{~mL}$ of a solution with potassium ferricyanide $\mathrm{K}_{3}\left[\mathrm{Fe}(\mathrm{CN})_{6}\right]$, $\mathrm{w}=2.5 \%$. Take a $400 \mathrm{~mL}$ beaker and focus the TIC on it. Turn off the light (or work in a big covered cardboard box) and fill both solutions simultaneously into the beaker.

\subsubsection{Observation and Remarks}

In the dark one can see a bright blue-greenish luminescence that lasts some time. It is the typical luminescence of luminol when being oxidized by hydrogen peroxide in an alkaline solution. In the reaction the 3-aminophthalate dianion is produced in its electronically excited state. It relaxes via emission of light at $\lambda=425 \mathrm{~nm}$ [7]. Iron(III)-ions enhance the luminescence. Students might know this from movies where crime scene investigators detect traces of blood by luminescence of luminol.

Contrary to the experiments before, one cannot see any change in the thermogram. This leads to the conclusion that no significant change in temperature takes place.

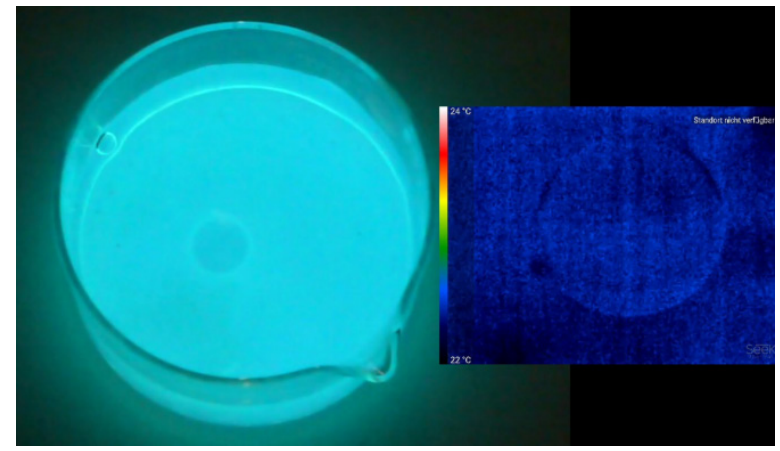

Figure 8. The generation of cold light in a chemiluminescence reaction is not accompanied by the emission of IR radiation

This is a nice demonstration of the emission of cold light in a chemiluminescence reaction, which in contrast to other light generating reactions such as combustions, is not accompanied by a release of heat.

From this insight, one could focus on other light emitting devices that emit cold light, e.g. organic or 
inorganic LEDs. Looking at these light sources and comparing them, e.g. with a tungsten light bulb, one can show that LEDs are more effective energy converters (Figure 9). This helps students understand why the EU has prohibited the import and sale of tungsten light bulbs.

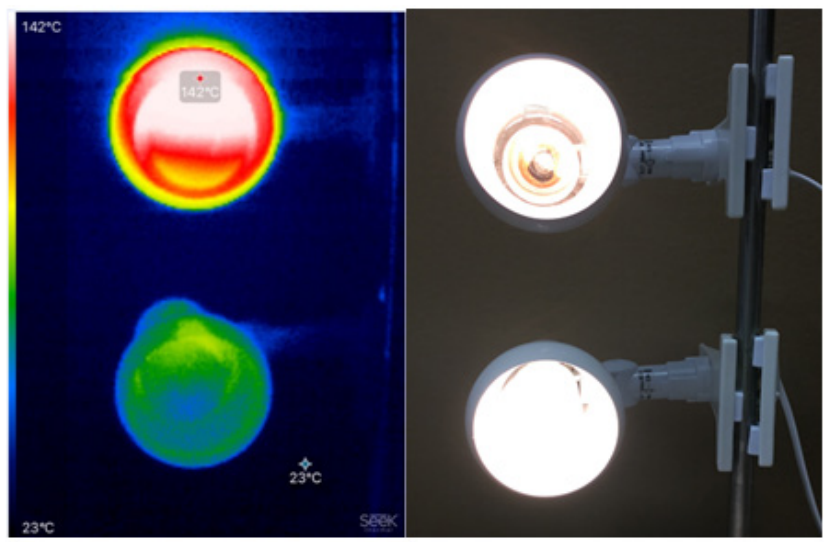

Figure 9. Tungsten light bulbs (top) release great amounts of heat, LED lamps (bottom) emit cold light.

\section{An E-book "Keeping track of heat"}

Since a part of our workgroup's activities focuses on
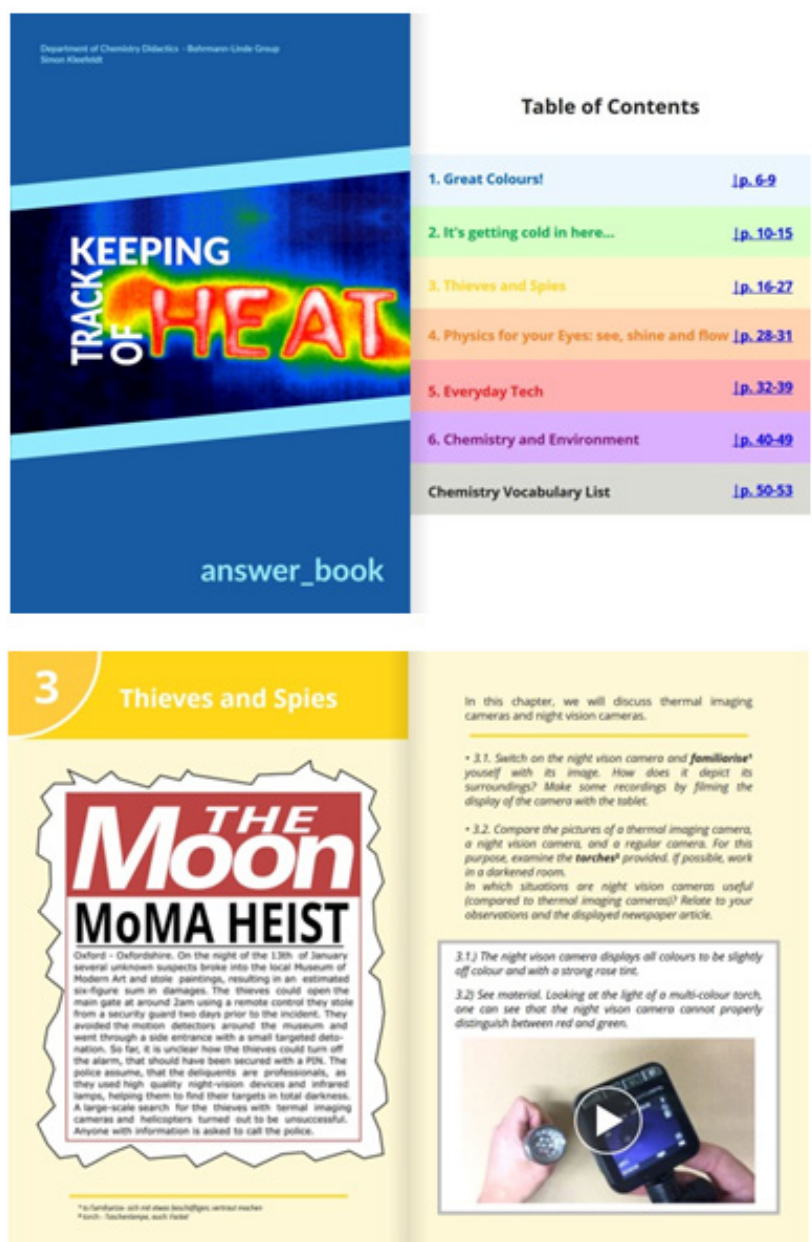

the development of print and digital learning and teaching media, we designed the e-book "Keeping track of heat" as a source on the use of TICs in the science classroom. It is freely available in English and German via our homepage [8]. E-books have the advantage that they offer static and dynamic information and that they can also be used for lab documentation [9]. Our e-book is offered in a full version for teachers and a student version. The full version includes videos and photographs of the experiments of the e-book, as well as answers to all questions or tasks in the book. Users who have the e-book in the student version on a tablet can photograph their own observations and include them in the e-book, having their individual lab work integrated as a basis for further reflections without a break in media. The e-book was made using the app Book Creator which is available as freeware. It enables the user to integrate texts, sound, photographs and videos. The e-book can be edited by students via the app Book Creator and saved as an epub-file. In this respect the ebook serves as an experimental tool (used to document lab work and take thermal images) as well as a learning tool [9]. In the app Book Creator there is an integrated readout function, so non-English speaking students can listen to the pronunciation of unknown words. It is also possible to convert the file into the pdf format, at the cost of interactivity though.
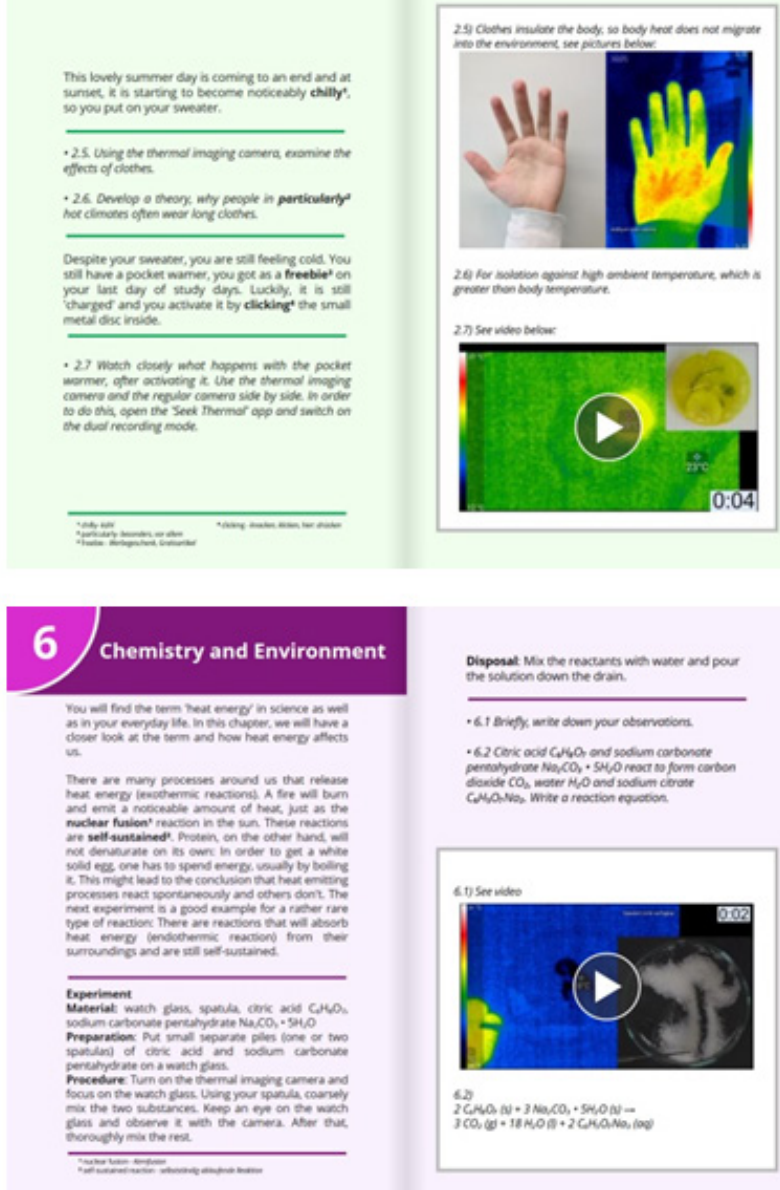

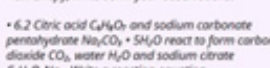

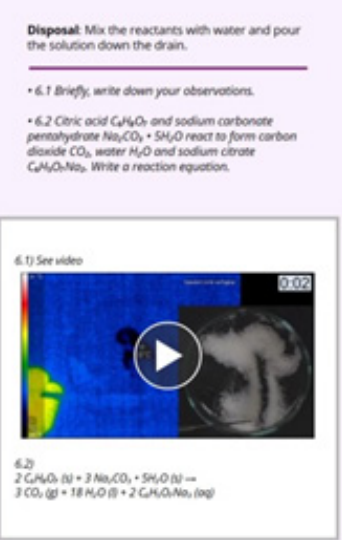

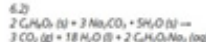

Figure 10. Selection of pages from the e-book "Keeping track of heat" from the full version for teachers [8] 
The e-book consists of six chapters focussing on topics from chemistry and physics (Figure 10). In each chapter there is a narrative setting in which experiments and tasks are embedded. The chapters can be worked through independently from each other, so students can individually choose topics, which contributes to differentiation in the classroom [10]. To get acquainted with the use of the TIC and thermograms, it is recommended to start with the first chapter. After an introduction into the TIC and thermograms, some introductory experiments are presented in chapter 1 . In chapter 2 the processes of transpiration, dogs' panting, crystallization in a pocket warmer, the insulating effect of textiles and the use of first aid thermal blankets are embedded in the setting of a visit to a pool on a hot summer day. Chapter 3 opens up with a newspaper article on a heist and deals with the difference between thermal imaging cameras and night vision cameras and detecting fake paintings. The relation of the colour and temperature of a glowing wire as well as the aspects absorption, reflection and transmission of heat is regarded in chapter 4. In chapter 5 one can compare LEDs as emitters of cold light with tungsten light bulbs and heat lamps with respect to the emitted heat energy and the light intensity, after having dealt with the chemiluminescence experiment with luminol. Chapter 6 finally deals with exothermic and endothermic reactions and dissolution processes, neutralisation enthalpy and thermal conductivity of metals typically used in chemistry classes.

Since the e-book is also designed for the bilingual chemistry classroom in German schools, there are some translations into German at the bottom of the main pages, as well as a chemical vocabulary list with translations from English into German at the end of the e-book.

\section{Conclusion}

It is increasingly easier to use thermal imaging cameras in the chemistry or science classroom, as TICs are available at reasonable prices. They can be connected with the students' own mobile devices, if the teacher follows a BYOD-concept (bring your own device). So schools do not even have to buy and maintain own devices and students on the other hand can experience their mobile devices as valuable educational tool, instead of using it mainly for social media or games. Thermal imaging cameras help the students to get access to a world that is usually hidden for human eyes due to a lack of ability of sensing in the IR region. So thermal energy can be visualized and chemical processes, which are characterized by a turnover of matter accompanied as well as by a turnover of thermal energy, can be experienced in an enhanced way.

\section{References}

[1] K.P. Möllmann, M. Vollmer, Infrared thermal imaging as a tool in university physics education" Eur.J.Phys. 28 (2007), 37-50.

[2] M. Vollmer, K.P. Möllmann, Teaching physics and understanding infrared thermal imaging, Proc.SPIE 10452 (2017).

[3] J. Haglund, F. Jeppsson, E. Melander, A-M. Pendrill, C. Xie, K.J. Schönborn, Infrared Cameras in Science Education, Infrared Physics \& Technology (2016).

[4] C. Xie, Visualizing Chemistry with Infrared imaging, Journal of Chemical Education, 88 (2011), 881-885.

[5] C. Bohrmann-Linde, S. Kleefeld, Chemische Reaktionen mit der Wärmebildkamera betrachtet, Nachrichten aus der Chemie, 66 (2018), 1182-1185.

[6] M. Vollmer, K.-P. Möllmann, Infrared Thermal Imaging Fundamentals, Research and Applications, 2. Edition, Wiley VCH Weinheim, 2018.

[7] D. Wöhrle, M.W. Tausch, W.-D. Stohrer, Photochemie, WileyVCH Weinheim 1998.

[8] C. Bohrmann-Linde, S. Kleefeld, Keeping track of heat, e-book available on http://chemiedidaktik.uni-wuppertal.de/index.php?id=4225\&L=1 (18.03.2019).

[9] J. Huwer, A. Bock, J. Seibert, The School Book 4.0: The Multitouch Learning Book as a Learning Companion. American Journal of Educational Research, 6, (2018), 763-772.

[10] N. Ulrich, e-books - Potentiale für den Umgang mit Diversität. In: S. Schanze, J. Groß (eds.), Lernprozesse mit digitalen Werkzeugen unterstützen. Perspektiven aus der Didaktik naturwissenschaftlicher Fächer. Hamburg, Joachim Hertz Stiftung (2017), 71-80

(C) The Author(s) 2019. This article is an open access article distributed under the terms and conditions of the Creative Commons Attribution (CC BY) license (http://creativecommons.org/licenses/by/4.0/). 